\title{
An unusual extraction; retrieval of a swallowed crown by appendicectomy
}

\author{
P. Glen, ${ }^{1}$ U. Ihedioha ${ }^{2}$ and I. Mackenzie ${ }^{3}$
}

We report the case of a patient who swallowed a crown and three weeks later presented with abdominal pain and fever. At operation his crown was found to be causing appendicitis. Foreign bodies have previously been reported as causing appendicitis but never a crown. We discuss the appropriateness of abdominal radiology in the management of such foreign bodies.

\section{INTRODUCTION}

Acute appendicitis remains the most common emergency surgical presentation requiring operative intervention. Foreign bodies within the resected appendix are uncommon; the most recent review of medical literature found 256 reported cases in the last 100 years and estimated the incidence at 1 in 20,000 appendicectomies. ${ }^{1}$ It would appear that gravity has prevented them travelling up the ascending colon and they may eventually become impacted within the lumen of the appendix. The most common foreign bodies are pins, lead shot, seeds and bones. There are no reported incidences of an accidentally swallowed crown causing appendicitis. We report a case where this occurred.

\footnotetext{
${ }^{*}-3$ Department of Surgery, Monklands District General Hospital, Monkscourt Avenue, Airdrie, Lanarkshire, ML6 0JS

${ }^{*}$ Correspondence to: Mr Paul Glen

Email:paul.glen@ntlworld.com
}

\section{Refereed Paper}

Accepted 15 June 2006

DOI: $10.1038 /$ bdj.2007.76

${ }^{\circ}$ British Dental Journal 2007; 202: 141-142

\section{CASE REPORT}

A 41-year-old, previously healthy man attended accident and emergency with a history of right iliac fossa pain for the last two days, with pyrexia and 'feeling hot and sweaty'. He had swallowed a porcelain post crown, three weeks previously while eating, and did not think that it had passed. On examination he was pyrexial and had signs of localised peritonism in the right iliac fossa. His white cell count was moderately elevated. Plain abdominal radiology was requested and the crown was visible (Fig. 1). The likely diagnosis was thought to be appendicitis but a perforation secondary to the crown was considered. He was taken to theatre soon afterwards, the appendix was removed and a foreign body was felt within the lumen. The pathologist opened this specimen and a photograph was taken which showed the crown within the inflamed lumen (Fig. 2). The patient went home 48 hours later after an uneventful recovery.

\section{DISCUSSION}

In general dental practice a swallowed foreign body is the second most common medical emergency not associated with general anaesthetic and 1.5-2.0

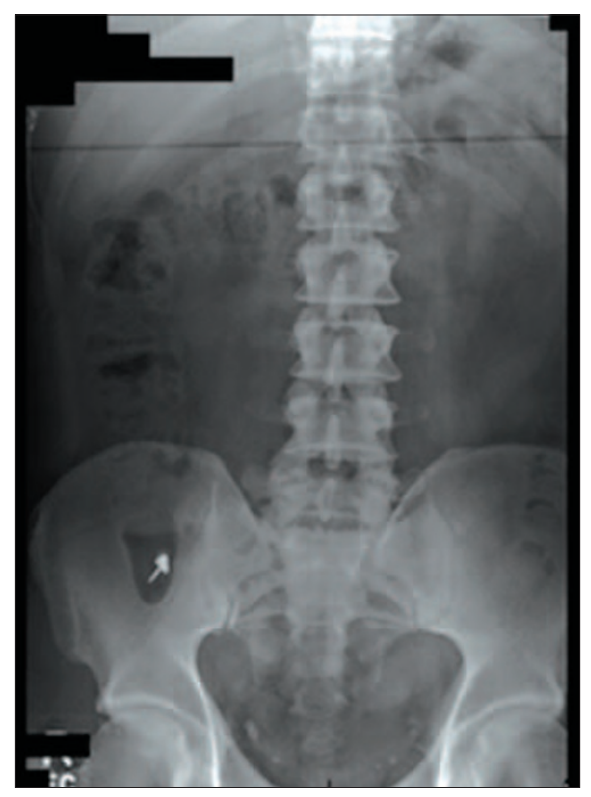

Fig. 1 Plain abdominal film

episodes will occur in a 40 year working life. Inhaled foreign bodies occur less frequently (0.06 episodes per 40 years), however, these figures emphasise the importance of airway protection during dental treatment. ${ }^{2}$

A patient that has swallowed a crown would not be expected to require any intervention. The complication we would perhaps see would be a small bowel 


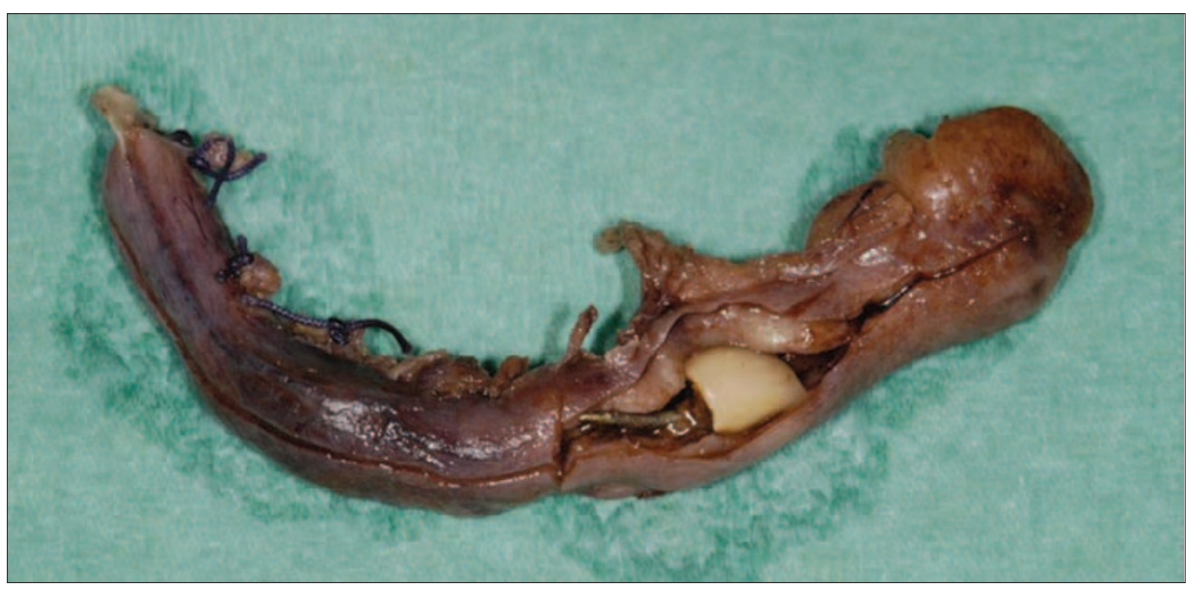

Fig. 2 Crown within opened appendix

perforation due to the post, however, this in itself would be unusual and the most likely sites would be the duodenum or terminal ileum/appendix.

Assessment of a swallowed foreign body in the accident and emergency department will take the form of plain radiology from the nasopharynx to the bottom of the pelvis and intervention is unlikely to be required if the foreign body has passed through the the highest likelihood of causing perforation or appendicitis. Ingested foreign bodies that get through the oesophagus will pass in the stool in 99\% of cases ${ }^{6}$ so this aggressive radiological assessment is probably not warranted. We would recommend that follow up after initial radiology is only required in symptomatic patients.

1. Klingler P J, Seelig M H, DeVault K R et al. Ingested foreign bodies within the appendix: a 100-year review of the literature. Dig Dis1998; 16: 308-314.

2. Atherton G J, McCaul J A, Williams S A. Medical emergencies in general dental practice in Great Britain. Part 1: their prevalence over a 10-year period. Br Dent J 1999; 186: 72-79.

3. Brown, L. Foreign bodies. In Wolfson A B, Hendey G W, Hendry P L et al. (eds). Harwood-Nuss' clinical practice of emergency medicine. Chapter 246. Philadelphia: Lippincott Williams \& Wilkins, 2005.

4. Schunk J E, Corneli H, Bolte R. Pediatric coin ingestions. A prospective study of coin location and symptoms. Am J Dis Child 1989; 143: 546-548.

5. Rothrock S G, Green S M, Harding M et al. Plain abdominal radiography in the detection of acute medical and surgical disease in children: a retrospective analysis. Pediatr Emerg Care 1991; 7: 281-285.

6. Pellerin D, Fortier-Beaulieu M, Gueguen J. The fate of swallowed foreign bodies: experience of 1,250 instances of sub-diaphragmatic foreign bodies in children. Progr Pediatr Radiol 1969; 2: 286-302. 